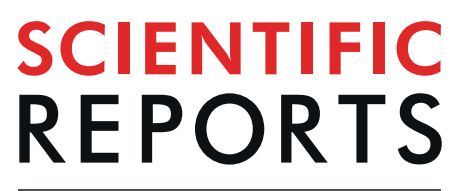

natureresearch

\title{
ESR as a monitoring method of the interactions between TEMPO-functionalized magnetic nanoparticles and yeast cells
}

\author{
Ryszard Krzyminiewski ${ }^{1}$, Bernadeta Dobosz ${ }^{1 *}$, Grzegorz Schroeder ${ }^{2}$ \& Joanna Kurczewska ${ }^{2}$ \\ Potential application of magnetic nanoparticles as drug carriers in medical treatment requires prior \\ determination of their effects on cells. In this work different spin labels and magnetic nanoparticles \\ functionalized with spin labels as well as their interaction with yeast cells were investigated using \\ electron spin resonance (ESR) method. ESR was demonstrated to be a suitable method for monitoring \\ of magnetic core and attached spin labels. Particular emphasis was placed on characterization of \\ endocytosis and redox processes running inside the cell, resulting in recombination of spin labels. Such \\ data could only be obtained at reduced temperature of ESR measurements.
}

\begin{abstract}
Nanomaterials are extensively studied for their use in various fields ${ }^{1,2}$. Biomedical applications of these materials, including new strategies in medical treatment and therapy ${ }^{3-5}$, are especially of great interest. Particularly promising is a potential role of nanoparticles as drug carriers ${ }^{6,7}$ in order to reduce therapeutic dose and deliver a drug directly to a desired location ${ }^{8,9}$. Nanomaterials with magnetic properties can be controlled by an appropriate magnetic field configuration ${ }^{10,11}$ that should facilitate targeted delivery of an attached drug.

The properties of magnetic nanoparticles are investigated using different methods ${ }^{12}$. However, penetration of nanoparticles into cellular structures and process of endocytosis are difficult to be monitored. Endocytosis is a complex phenomenon of cellular uptake of various particles ${ }^{13-16}$, during which plasma membrane invaginators to form vesicles that are essential for delivery of many substances into a cell. It can be also potentially applied for delivery of nanoparticles functionalized with drugs to cellular structures. Currently nanoparticles with attached fluorescent marker are used. They are characterized by confocal microscopy, as a direct technique of assessing the penetration of those nanoparticles inside the cell, and indirect biochemical methods ${ }^{17-21}$. Therefore, other methods to study endocytosis are currently searched.

Electron spin resonance (ESR) is commonly used for characterization of physical properties of various nanomaterials ${ }^{22-28}$, including functionalized magnetic nanoparticles ${ }^{29,30}$. The magnetic nanoparticles with attached spin label (free radical) are characterized by two areas that can be described by ESR measurements - magnetic core and free radical. Moreover, the method can be applied to observe the differences resulting from interaction between the material surface and environment ${ }^{31,32}$. Therefore, interaction of nanoparticles with cells, including their penetration into cells and the process of endocytosis, should be able to be monitored on the basis of ESR results.

The aim of this study was to show that electron spin resonance spectroscopy can be used not only to control the properties of functionalized magnetic nanoparticles but also to evaluate their interaction with model cells (yeast cells).
\end{abstract}

\section{Results}

Characterization of magnetic nanomaterials. Bare and coated magnetite nanoparticles were characterized by several physicochemical methods. All magnetic nanoparticles studied show bands in Fourier transform infrared (FTIR) spectra characteristic for iron(II, III) oxide $\left(\mathrm{Fe}_{3} \mathrm{O}_{4}\right)$. Strong and broad band at $575 \mathrm{~cm}^{-1}$, observed in the spectrum of bare magnetite $\mathrm{Fe}_{3} \mathrm{O}_{4}$ and silica coated material $\mathrm{Fe}_{3} \mathrm{O}_{4} @ \mathrm{SiO}_{2}$ (Fig. S1 in Supplementary information), is assigned to $\mathrm{Fe}-\mathrm{O}$ vibration from the magnetite phase. The bands appearing at

${ }^{1}$ Medical Physics Division, Faculty of Physics, Adam Mickiewicz University in Poznań, Uniwersytetu Poznańskiego 2, 61-614, Poznań, Poland. 'Faculty of Chemistry, Adam Mickiewicz University in Poznań, Uniwersytetu Poznańskiego 8,61-614, Poznań, Poland. *email: benia@amu.edu.pl 

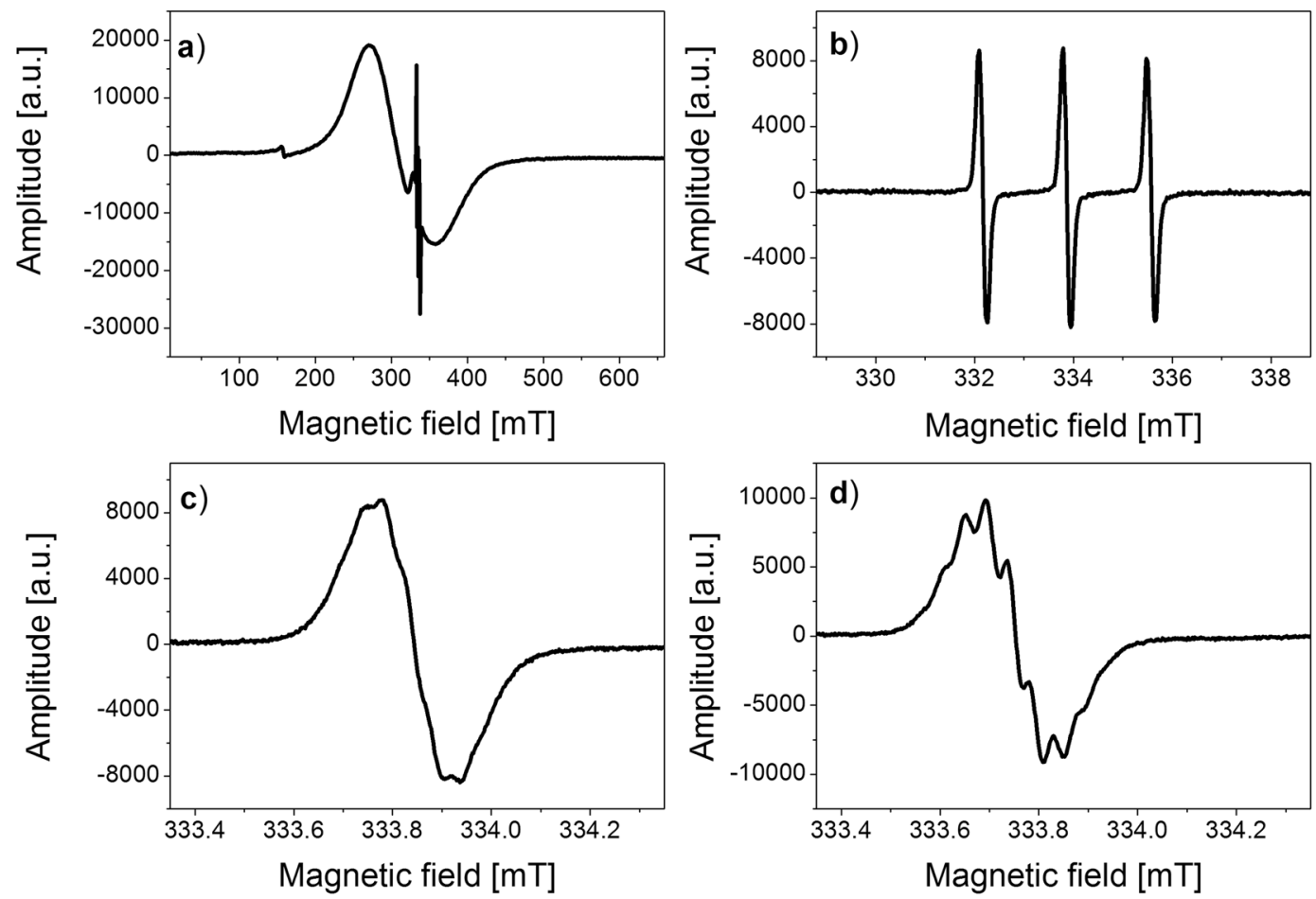

Figure 1. ESR spectra of spin label (Table 1) recorded at $297 \mathrm{~K}$ : (a) attached to magnetic nanoparticles (wide range of magnetic field, $650 \mathrm{mT})$, (b) narrow range of magnetic field $(10 \mathrm{mT})$ in water, $(\mathbf{c})$ central line of triplet shown in Fig. $1 \mathrm{~b}$ in water $(1 \mathrm{mT}),(\mathbf{d})$ central line of triplet shown in Fig. $1 \mathrm{~b}$ with yeast $(1 \mathrm{mT})$.

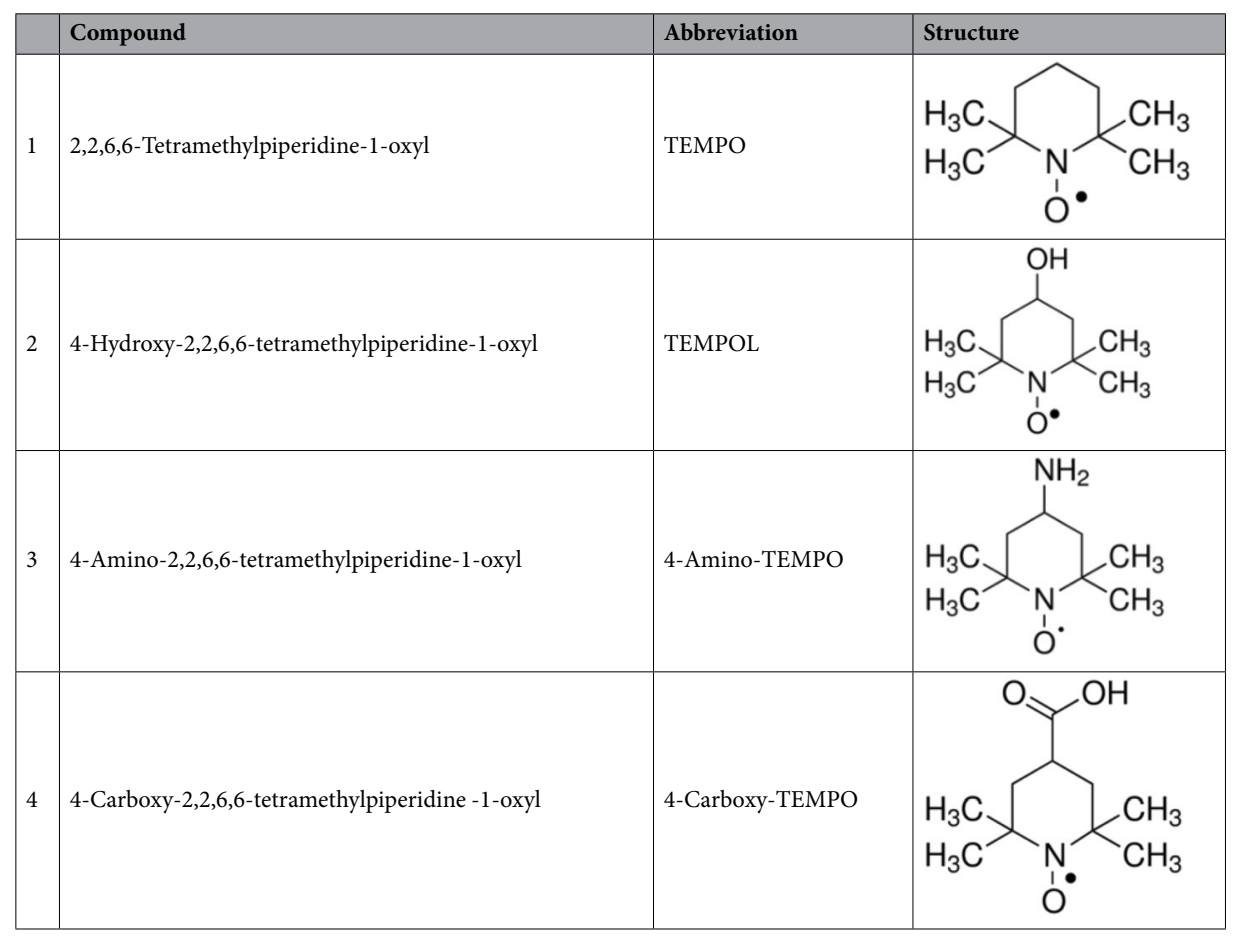

Table 1. The spin labels (free radicals) studied.

3420 and $1639 \mathrm{~cm}^{-1}$ are related to $-\mathrm{OH}$ stretching vibrations (surface hydroxyl groups and water molecules). Silica coating is confirmed by a strong band at $1104 \mathrm{~cm}^{-1}$ ( $\mathrm{Si}-\mathrm{O}-\mathrm{Si}$ asymmetric stretching vibration). Magnetic silica nanoparticles $\mathrm{Fe}_{3} \mathrm{O}_{4} @ \mathrm{SiO}_{2}$ were further coated with dextran derivatives containing free radicals: 4-Amino2,2,6,6-tetramethylpiperidine-1-oxyl (4-Amino-TEMPO) and 4-Hydroxy-2,2,6,6-tetramethylpiperidine-1-oxyl 


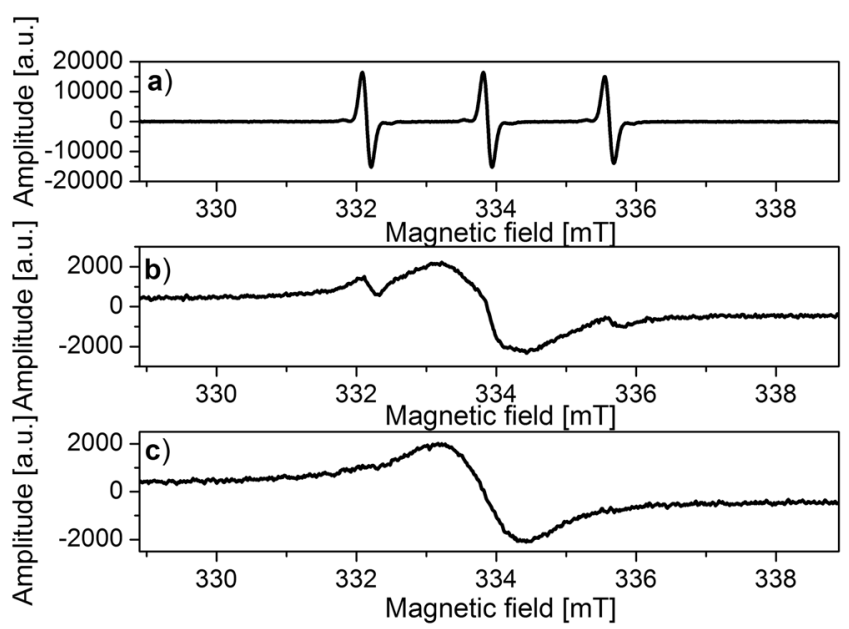

Figure 2. ESR spectra of TEMPO in water recorded at various temperatures: (a) $276 \mathrm{~K}$, (b) $260 \mathrm{~K}$, (c) $250 \mathrm{~K}$.

(TEMPOL), i.e. Dextran-NH-TEMPO and Dextran-O-TEMPO. However, the IR spectra of $\mathrm{Fe}_{3} \mathrm{O}_{4} @ \mathrm{SiO}_{2} @$ Dextran-NH-TEMPO and $\mathrm{Fe}_{3} \mathrm{O}_{4} @ \mathrm{SiO}_{2} @$ Dextran-O-TEMPO are very similar, and differ from the previous ones only by the presence of a new signal at $2935 \mathrm{~cm}^{-1}$ assigned to the $\mathrm{C}-\mathrm{H}$ stretching vibrations of alkyl groups. It confirms the presence of an organic coating but strong overlapping signals from $\mathrm{Fe}_{3} \mathrm{O}_{4}$ and $\mathrm{SiO}_{2}$ prevent observation of peaks attributed to functionalized dextran. Therefore, the FTIR spectra of dextran and dextran-NH ( or O)-TEMPO were also compared. In the spectrum of dextran, the broad signal at $3411 \mathrm{~cm}^{-1}$ is assigned to $\mathrm{OH}$ stretching vibrations of polysaccharide. The signals at $2935 \mathrm{~cm}^{-1}(-\mathrm{CH}$ stretching $)$ and $1436 \mathrm{~cm}^{-1}(\mathrm{H}-\mathrm{C}-\mathrm{OH}$ deformation) are characteristic of $\mathrm{C}-\mathrm{H}$ bonds. The bands at 1165,1118 and $1021 \mathrm{~cm}^{-1}$ correspond to vibration of $\mathrm{C}-\mathrm{O}-\mathrm{C}$ bond and glycosidic bridge, $\mathrm{C}-\mathrm{O}$ vibration and chain flexibility respectively. The glucopyranose ring deformation is confirmed by the presence of characteristic bands at 917,853 and $769 \mathrm{~cm}^{-1}$. Additional bands at $1577(1584) \mathrm{cm}^{-1}$ in the spectra of dextran-NH (or O)-TEMPO correspond to the stretching mode of carbonyl. The signals related to the free radical are located at 1262 (C-N group in TEMPO) and $1365 \mathrm{~cm}^{-1}(\mathrm{~N}-\mathrm{O}$ free radical in TEMPO).

The crystallinity of the magnetic materials was investigated by X-ray diffraction (XRD). The samples are characterized by the presence of six diffraction peaks of $\mathrm{Fe}_{3} \mathrm{O}_{4}$ at $2 \Theta 30.3^{\circ}, 35.6^{\circ}, 43.3^{\circ}, 53.7^{\circ}, 57.2^{\circ}$ and $62.9^{\circ}$ corresponding to the crystal planes of (220), (311), (400), (422), (511) and (440) respectively. The crystalline phase is stable during coating with silica and dextran because the same diffraction peaks are observed in XRD patterns of bare and coated $\mathrm{Fe}_{3} \mathrm{O}_{4}$. The only visible change compared to bare $\mathrm{Fe}_{3} \mathrm{O}_{4}$, is additional broad halo at $2 \Theta 22^{\circ}$ observed for $\mathrm{Fe}_{3} \mathrm{O}_{4} @ \mathrm{SiO}_{2}$ (Fig. S2). It is a typical feature of amorphous $\mathrm{SiO}_{2}$, while crystalline $\mathrm{SiO}_{2}$ phase is not found. In the XRD patterns of dextran coated materials, the peaks showed no visible change in relation to $\mathrm{Fe}_{3} \mathrm{O}_{4} @ \mathrm{SiO}_{2}$ and no dextran phase was found. This result is in agreement with literature reports on dextran coated $\mathrm{Fe}_{3} \mathrm{O}_{4}$ nanoparticles ${ }^{33}$. According to transmission electron microscope (TEM) images, the average dimension of bare $\mathrm{Fe}_{3} \mathrm{O}_{4}$ nanoparticles was in $20-25 \mathrm{~nm}$ range, while the coated ones were characterized by a larger size (not exceeding $50 \mathrm{~nm}$ ).

The composition of $\mathrm{Fe}_{3} \mathrm{O}_{4}$ and $\mathrm{Fe}_{3} \mathrm{O}_{4} @ \mathrm{SiO}_{2}$ was investigated by energy dispersive X-ray (EDX) spectroscopy. EDX pattern of bare magnetite shows the presence of $\mathrm{Fe}$ and $\mathrm{O}$ elements demonstrating the purity of iron(II, III) oxide nanoparticles. $\mathrm{Fe}_{3} \mathrm{O}_{4} @ \mathrm{SiO}_{2}$ contains also Si peak as en effect of silica coating. Additional $\mathrm{Cu}$ and $\mathrm{C}$ peaks originate from the carbon copper grid (Fig. S3).

ESR spectra of studied solutions. ESR spectra of the nanoparticles solutions at room temperature showed a typical two-component structure (Fig. 1). The signal from the magnetic core was visible in the whole spectral range $(650 \mathrm{mT})$ (Fig. 1a), while in the narrow spectral range $(10 \mathrm{mT})$ (Fig. 1b) - the one characteristic for spin labels in the form of three hyperfine lines formed as a result of the hyperfine interaction of unpaired electron spin $(\mathrm{S}=1 / 2)$ with a nitrogen atom nucleus $\left(\mathrm{I}_{\mathrm{N}}=1\right)$.

The studies of the nanoparticles functionalized with various spin labels carried out at room temperature showed poor differentiation of ESR spectral structure and spectroscopic parameters (spectroscopic splitting factor g, hyperfine splitting constant A, spectral structure, correlation times etc.) regardless of the compound attached to the magnetic core. The differences were only observed for the so-called superhyperfine structure or hyperfine interaction of an unpaired electron with further nuclei of hydrogen atoms in solutions of nanoparticles mixed with yeast cells, aqueous solutions of functionalized nanoparticles and various types of spin labels: TEMPO (2,2,6,6-Tetramethylpiperidine-1-oxyl), TEMPOL, 4-Amino-TEMPO and 4-Carboxy-TEMPO (4-Carboxy2,2,6,6-tetramethylpiperidine -1-oxyl), (Fig. 1c,d). The superhyperfine structure was better defined for the compounds with functional groups $\left(-\mathrm{OH},-\mathrm{NH}_{2},-\mathrm{COOH}\right)$, especially in solutions with yeast cells (compare Fig. 1c,d).

Therefore, in order to diversify the ESR spectra depending on the environment and to visualize their interaction with yeast cells, temperature measurements for the solutions of spin labels, spin labels attached to nanoparticles and the solutions of nanoparticles with yeast cells were performed (Figs. 2-4). Yeast cells with spin labels and with nanoparticles were always incubated at $37^{\circ} \mathrm{C}$. ESR measurements of incubated samples were carried 

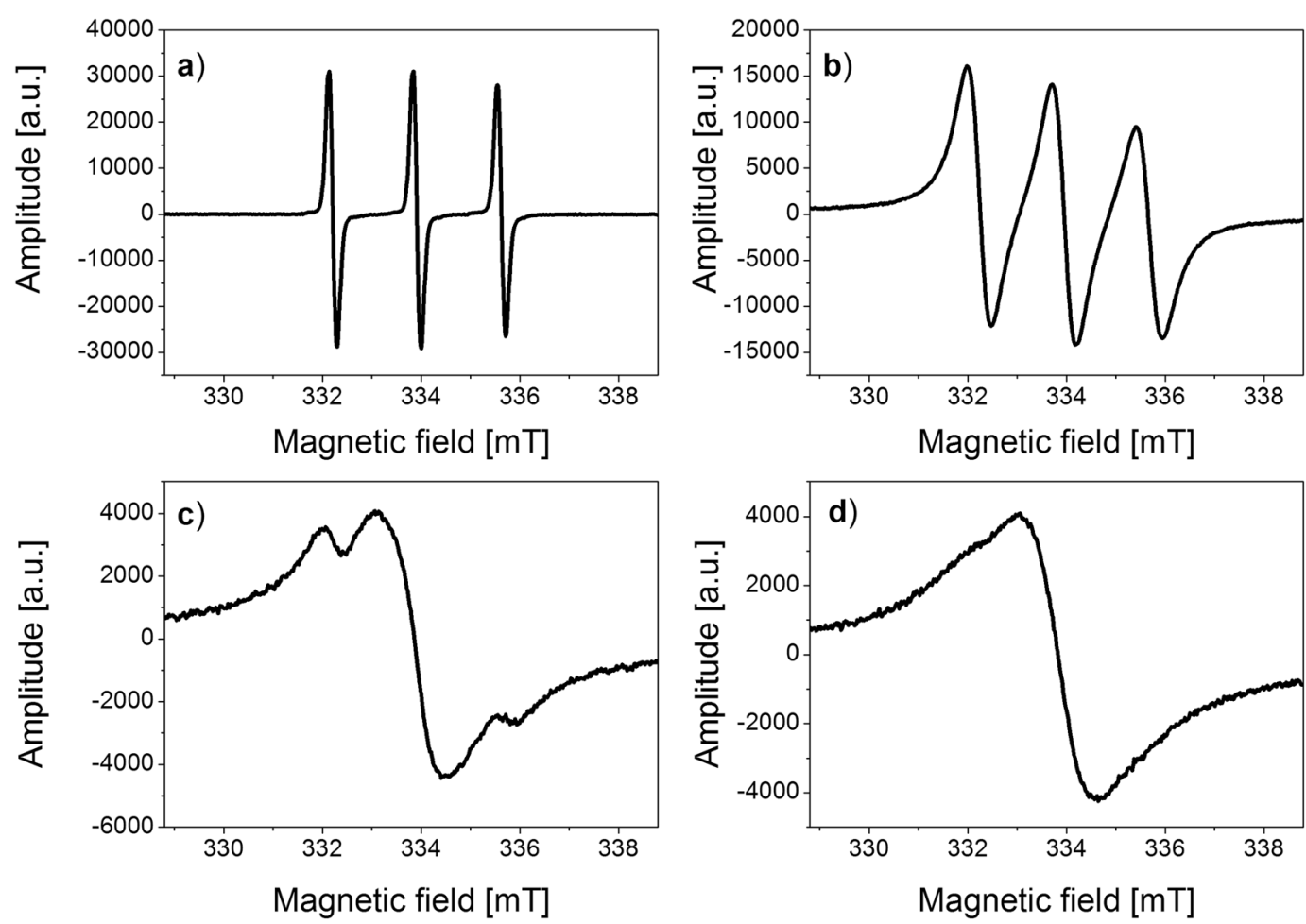

Figure 3. ESR spectra of TEMPOL in water recorded at various temperatures: (a) $276 \mathrm{~K}$, (b) $250 \mathrm{~K}$, (c) $240 \mathrm{~K}$, (d) $230 \mathrm{~K}$.
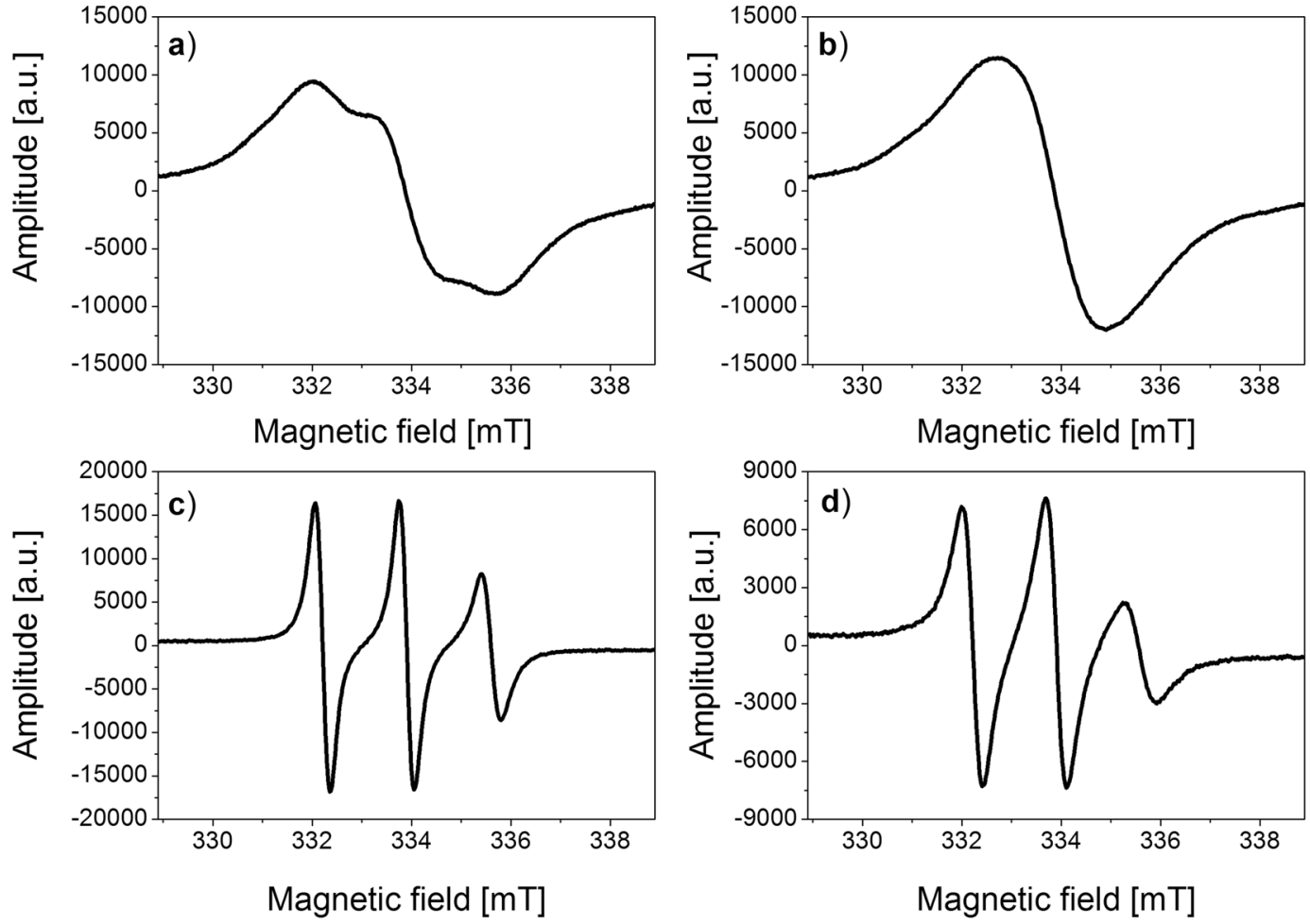

Figure 4. ESR spectra of $\mathrm{Fe}_{3} \mathrm{O}_{4} @ \mathrm{SiO}_{2} @$ Dextran-O-TEMPO: (a) in water at $250 \mathrm{~K}$, (b) in water at $240 \mathrm{~K},(\mathbf{c})$ with yeast at $250 \mathrm{~K}$, (d) with yeast at $240 \mathrm{~K}$. 


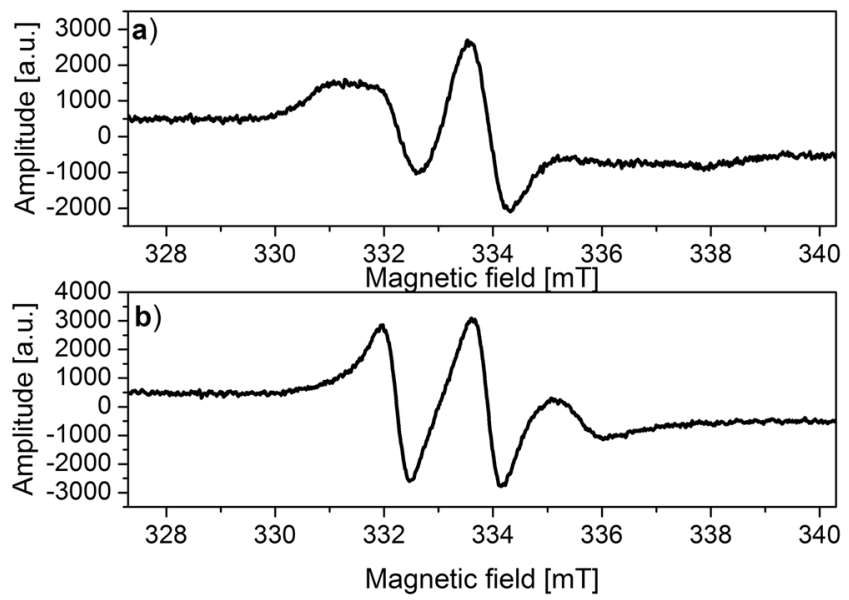

Figure 5. ESR spectra of $\mathrm{Fe}_{3} \mathrm{O}_{4} @ \mathrm{SiO}_{2} @ D$ Dextran-NH-TEMPO in water mixed with yeast cells recorded at $240 \mathrm{~K}$ : (a) immediately after mixing, (b) after $4 \mathrm{~h}$ of incubation.

out at low temperatures, by slowing down the molecular dynamics of the nanoparticles, which should result in differentiation of spectroscopic parameters depending on the environmental conditions. Additionally, it was also observed by optical microscope that the sample freezing during ESR measurement did not cause the rupture of yeast cells membrane.

Initially, changes in the structure and parameters of ESR spectra of spin labels were examined (Figs. 2 and 3).

The changes of the hyperfine structure as a function of temperature for the solutions of nanoparticles functionalized with spin labels with or without yeast cells, differ significantly from those in the solutions of spin labels (see Figs. 3 and 4). ESR spectra of the samples studied are significantly different after incubation with yeast cells (Fig. 4).

Endocytosis and recombination of spin labels. The temperature $240 \mathrm{~K}\left(-33^{\circ} \mathrm{C}\right)$ was found to be optimal for differentiation of ESR spectra of the functionalized nanoparticles solution. On the other hand, at room temperature such an effect could not be obtained because the spectroscopic parameters of spin labels (hyperfine splitting, g-factor and spectral structure) were very similar.

The process of yeast incubation with functionalized nanoparticles and especially the time of this incubation had a decisive impact on the structure of the ESR spectrum.

ESR spectra of the nanoparticles studied mixed with yeasts, incubated for about 1 minute (at room temperature), measured at $240 \mathrm{~K}$ show a complex structure consisting of radicals differing in molecular dynamics (Fig. 5a).

Incubation time had an impact not only on the structure of ESR spectra but also on reducing the intensity of ESR signals derived from spin labels. This allowed the determination of the recombination rate of spin labels during incubation. An example of the rate of recombination of incubated solution yeast-TEMPOL was shown in Fig. 6.

Figure 7 presents the differences observed in the intensities of ESR signals in time of incubation for three studied solutions.

Confocal microscope pictures. In order to confirm the endocytosis process of functionalized magnetic nanoparticles into yeast cells, magnetic nanoparticles containing fluorescein (Fluorescein isothiocyanate, FTIC), $\mathrm{Fe}_{3} \mathrm{O}_{4} @ \mathrm{SiO}_{2} @ \mathrm{FITC}$ nanoparticles were used. The pictures taken from confocal microscope (Fig. 8) prove that pure yeast cells (Fig. 8a,b) did not show fluorescence, while the ones incubated previously with $\mathrm{Fe}_{3} \mathrm{O}_{4} @ S \mathrm{~S}_{2} @$ FITC nanoparticles gave an opposite effect (Fig. 8c,d). The results confirm that the nanoparticles entered the cells.

\section{Discussion}

Figure 1 illustrates that the superhyperfine structure is better enhanced for solution $\mathrm{Fe}_{3} \mathrm{O}_{4} @ \mathrm{SiO}_{2} @$ Dextran-NH-TEMPO - yeast cells (Fig. 1d). The experiments performed at low ambient $\mathrm{O}_{2}$ level confirmed no influence of oxygen level decrease during yeast fermentation on better resolution of ESR line in the sample $\mathrm{Fe}_{3} \mathrm{O}_{4} @ \mathrm{SiO}_{2} @$ Dextran-NH-TEMPO with yeast cells.

The values of spectroscopic parameters for all samples studied are approximately the same and the superhyperfine structure is best visible for $\mathrm{Fe}_{3} \mathrm{O}_{4} @ \mathrm{SiO}_{2} @$ Dextran-NH-TEMPO - yeast cells solution. The parameters were found to be: spectroscopic splitting factor $\mathrm{g}=2.168$ and the line width $\Delta \mathrm{H}=87 \mathrm{mT}$ for magnetic core, while for spin labels - spectroscopic splitting factor $\mathrm{g}=2.0058$, hyperfine splitting constant for a triplet $\mathrm{A}=1.71 \mathrm{mT}$ and superhyperfine splitting constant $\mathrm{A}_{\mathrm{s}}=0.04 \mathrm{mT}$.

These studies allowed to evaluate the interaction of nanoparticles with cells and therefore the process of endocytosis, as well as the interaction of spin labels attached to nanoparticles with metabolic processes in cells.

A significant decrease in TEMPOL intensity was observed in TEMPOL - yeast solution. At the beginning of incubation at $37^{\circ} \mathrm{C}$ the signal was significant and after 60 minutes the intensity of the signal was about $6 \%$ of the 


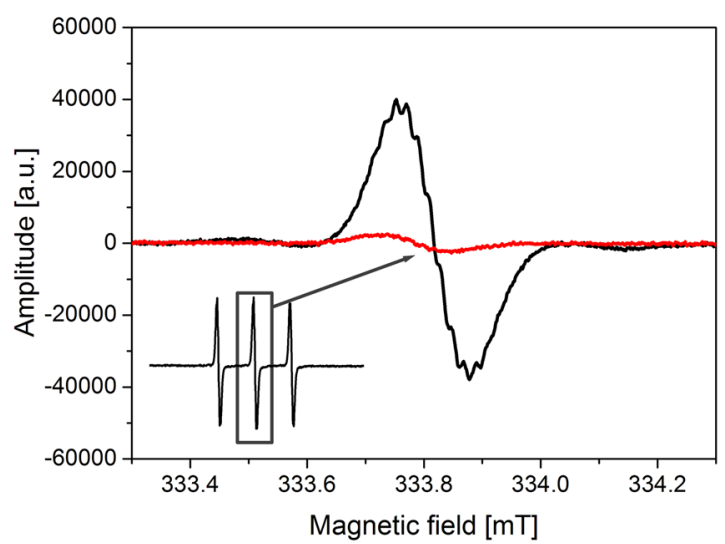

Figure 6. ESR spectra of TEMPO incubated with yeast cells recorded at $295 \mathrm{~K}$ : central line of triplet immediately after mixing (black line) and central line of triplet after 60 minutes (red line).

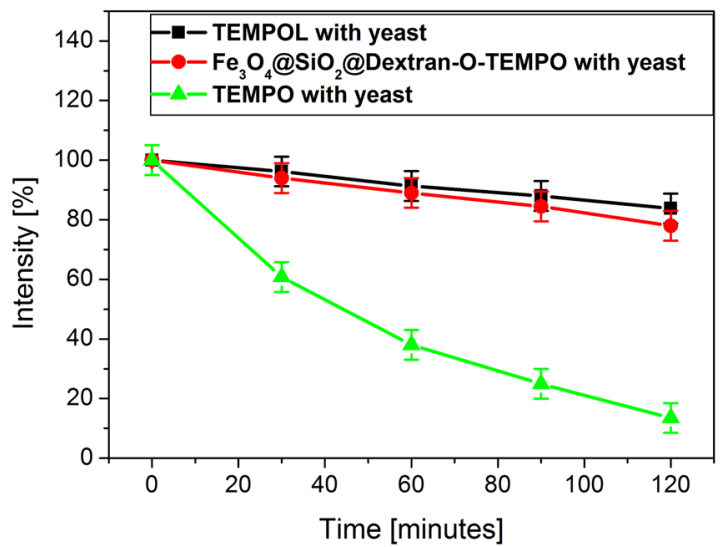

Figure 7. The differences observed in the intensities of ESR signals in time for three studied solutions: yeast cells with TEMPOL, yeast cells with $\mathrm{Fe}_{3} \mathrm{O}_{4} @ S_{2} \mathrm{O}_{2} @$ Dextran-O-TEMPO and yeast cells with TEMPO (error bars: the error of ESR signal intensity was taken as $\pm 5 \%$ ).

initial intensity (Fig. 6). It proves that the process of endocytosis and cellular metabolism were very intensive in this case. Moreover, the rate of endocytosis of the nanoparticles functionalized with TEMPOL and yeast is much slower compared to the one of unbound TEMPOL - yeast solution, hence endocytosis for free TEMPOL molecules is much faster.

The recombination process of TEMPOL affects rate of endocytosis and penetration of a spin label into the cell, as well as rate and mechanism of cellular metabolism. It results in reduction of a spin label and structure of ESR spectra.

The exemplary spectra (Figs. 2 and 3 ) for the solutions of free TEMPO and TEMPOL molecules show the broadening of three components of the hyperfine spectrum as the temperature of the solution decreases. In temperature $240 \mathrm{~K} / 230 \mathrm{~K}$ the hyperfine structure disappears and is replaced by a single line (Figs. $2 \mathrm{c}$ and $3 \mathrm{~d}$ ).

The changes observed in the structure of the ESR spectra after temperature decreasing, result from broadening of the spectral components as an effect of dipole interactions. Finally, the exchange interactions between the spins of unpaired electron begin to dominate which ultimately leads to the disappearance of the hyperfine structure and the appearance of a single line ${ }^{34-37}$. Similar behavior was observed in literature for the spectra of different spin labels at room temperature in the presence of $\mathrm{CrO}_{\mathrm{x}}$ compounds ${ }^{34-37}$. The presence of $\mathrm{CrO}_{\mathrm{x}}$ in the solution results in broadening of the components of the hyperfine spectrum of spin labels and acts as EPR line broadening. $\mathrm{CrO}_{\mathrm{x}}$ does not pass through the cell membranes. Therefore the changes of the hyperfine structure of spin labels, caused by its interaction with $\mathrm{CrO}_{\mathrm{x}}$ in the solution containing cells, indicate that the spin labels did not enter the cell and remain in the solution outside the cell. The reduction of the rotational dynamics of the spin labels, caused by the presence of $\mathrm{CrO}_{x}$, and the increase of the Heisenberg exchange interaction result in initial expanding and followed by narrowing of individual hyperfine structure triplet lines. It finally leads to the disappearance of this structure and the appearance of a single line. It should be emphasized that this broadening of the spectrum was induced artificially by adding $\mathrm{CrO}_{\mathrm{x}}$ to the cells solution and it proved the lack of TEMPO penetration inside the cells, i.e. the absence or very slow endocytosis. This suggests that such behavior of the spin labels spectra in the nanoparticles-cells solution at low temperatures would indicate that the nanoparticles do not interact with the cells in the process of endocytosis and behave similarly to pure solution without cells. 

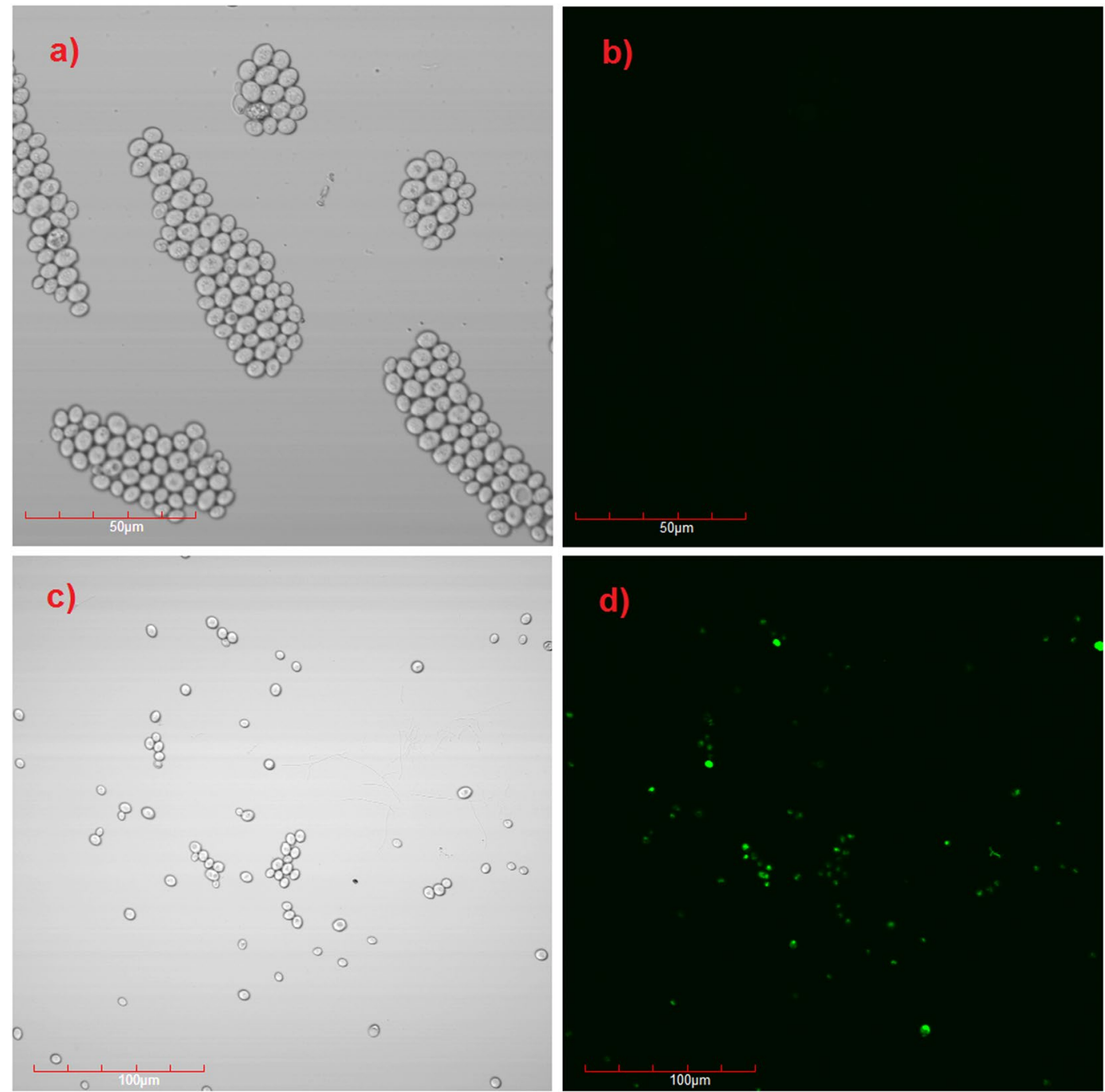

Figure 8. Confocal fluorescent imaging of FITC labeled nanoparticles in yeast cells: (a,b) yeast cells without nanoparticles, (c,d) yeast cells with $\mathrm{Fe}_{3} \mathrm{O}_{4} @ \mathrm{SiO}_{2} @ \mathrm{FITC}$ nanoparticles.

In the present study, the broadening of the hyperfine components of the ESR spectrum with decreasing temperature is only observed for solutions of unbound spin labels. At temperatures below $240 \mathrm{~K}$, the exchange interactions between the spin label molecules become a significant factor that affects the narrowing of the entire spectrum. This dominance of exchange interactions is confirmed by the overall width of the spectrum of a single line $\Delta \mathrm{H}=1.57 \mathrm{mT}$, which is much smaller than the hyperfine splitting constant of the triplet $\mathrm{A}=1.71 \mathrm{mT}$ (Fig. 3).

The spectral structure (Figs. 2-4) shows that the molecular dynamics mechanisms are different for the solutions of unbound spin labels, functionalized nanoparticles without and the ones with yeast cells. As an example, the temperature changes for the solution of free TEMPOL and the one attached to the nanoparticles were compared. The structure of the ESR spectrum for both solutions analyzed differ significantly as temperature decreases. There are two phases in the solutions discussed: the first one represented by broadening of three components of TEMPOL and nanoparticles spectra (Figs. 3 and 4) and the second one manifested by domination of Heisenberg exchange interactions between the radicals. In the solution of TEMPOL in $240 \mathrm{~K}$, two types of radicals are distinguished: first one with narrowed spectrum width $1.64 \mathrm{mT}$ after Heisenberg's exchange interactions, while the others are narrowed with complete splitting of extreme lines around $3.2 \mathrm{mT}$. On the other hand, the nanoparticles solution in $240 \mathrm{~K}$ is characterized by the presence of only one line (width of $2.2 \mathrm{mT}$ ). It indicates much weaker interactions in the nanoparticles studied compared to the solution of unbound TEMPOL. In TEMPOL functionalized nanoparticles, the molecules of free radicals are separated from each other and exchange interactions between them are difficult.

The differences observed are caused by extension of correlation time during sample cooling. It confirms strong interaction of the nanoparticles with the yeast cells. It could be explained by penetration of the nanoparticles into the cell, probably to the endosome. The nanoparticles functionalized with TEMPOL should have sufficient freedom of rotation in the endosome at $240 \mathrm{~K}$. The correlation time for these nanoparticles, estimated on the basis of ESR spectrum, at $240 \mathrm{~K}$ is $6 \times 10^{-9} \mathrm{~s}$. 
As it was mentioned earlier, spectroscopic parameters such as hyperfine splitting, g-factor and spectral structure at room temperature did not show significant differences depending on whether the spin labels were attached to the nanoparticle core or were incubated with yeast cells, etc. However, differentiation was only achieved using a reduced temperature. When the measurement temperature of the studied samples was lowered to $240 \mathrm{~K}$, a clear differentiation of ESR spectra parameters of spin labels was obtained (Fig. 5).

Three lines with shorter correlation time (so-called narrow) and three others that correspond to a longer correlation time (so-called broad) (Fig. 5a) were observed just after mixing the nanoparticle solution with yeast cells. After the sample incubation (4hours) at $37^{\circ} \mathrm{C}$ (Fig. 5b), the signals with a long correlation time disappeared, while the ones with a shorter correlation time were still observed. It probably results from different location of the nanoparticles studied. The so-called narrow triplet is derived from the nanoparticles incorporated into cellular organelles (e.g. endosomes), whereas a broad triplet originates from the nanoparticles associated with the cell membrane or the ones present in the non-cellular environment. The above interpretation is confirmed by measurements of the nanoparticles solution mixed at about $275 \mathrm{~K}\left(2^{\circ} \mathrm{C}\right)$. In such conditions, very fast endocytosis process is severely slowed down and the double structure of the ESR spectrum is clearly visible.

Thus ESR was found to be a suitable method for evaluation of endocytosis processes. However, a thorough analysis of this fast process requires further work using solutions at low temperatures in order to slow down or stop endocytosis.

The results of research studies on endocytosis of spin label in red blood cells ${ }^{38}$ indicated easy penetration of spin labels into the membrane of the cell and their reduction to a non-radical form in the process of cellular metabolism. Therefore the process of endocytosis and cellular metabolism result in a reduction of ESR signal intensity. Soule et al. ${ }^{38}$ showed that after 60 minutes of incubation of red blood cells with TEMPOL, the intensity of the ESR signal from TEMPOL dropped to about $40 \%$ of initial concentration. Thus, ESR could determine the kinetics of TEMPOL reduction occurring in the process of endocytosis and cellular metabolism.

Therefore ESR spectra changes were measured for solutions incubated at $37^{\circ} \mathrm{C}$. The zero point on the graph Fig. 7 shows the intensity of ESR signals for the initial moment, after mixing yeast cells and the nanoparticles solutions incubated at $275 \mathrm{~K}$. Such a low temperature stops endocytosis process ${ }^{39}$. The next points on the graph refer to samples incubated at $37^{\circ} \mathrm{C}$.

\section{Conclusions}

The ESR method allows to study the properties of magnetic nanoparticles functionalized with spin labels. Therefore the magnetic core and the dynamics of the attached spin labels can be precisely monitored.

ESR measurement of the samples containing magnetic nanoparticles functionalized with spin labels at $240 \mathrm{~K}$ allowed evaluation of their properties and dynamics in various environments. The same measurements at room temperature would be unlikely to carry out due to fast rotation of spin label molecules.

Moreover ESR measurement at $240 \mathrm{~K}$ of the samples containing functionalized magnetic nanoparticles with yeast cells allowed evaluation of the endocytosis and redox processes inside the cell, responsible for recombination of spin labels.

\section{Methods}

Materials. The spin labels used in the studies are presented in Table 1 . The free radicals were purchased from Sigma-Aldrich.

The functionalized magnetic nanoparticles. Synthesis procedure. $\mathrm{FeCl}_{3} \cdot 6 \mathrm{H}_{2} \mathrm{O}$ and $\mathrm{FeCl}_{2} \cdot 4 \mathrm{H}_{2} \mathrm{O}$, hexamethylene diisocyanate, tetraethyl orthosilicate (TEOS), Dextran and solvents were purchased from Sigma-Aldrich. Other chemicals were the analytic grade reagents commercially available and used without further purification. Aqueous solutions were prepared with distilled water.

The synthesis process of iron(II,III) oxide $\left(\mathrm{Fe}_{3} \mathrm{O}_{4}\right)$ nanoparticles coated with dextran bearing chemically bounded 4-Amino-TEMPO $\left(\mathrm{Fe}_{3} \mathrm{O}_{4} @ \mathrm{SiO}_{2} @ \mathrm{Dextran}-\mathrm{NH}-\mathrm{TEMPO}\right)$ consisted of several steps.

The mixture of $15 \mathrm{~mL}$ of $0.02 \mathrm{M} \mathrm{FeCl}_{2}$ and $0.04 \mathrm{M} \mathrm{FeCl}_{3}\left(\left[\mathrm{Fe}^{2+}\right]:\left[\mathrm{Fe}^{3+}=1: 2\right)\right.$ was stirred in a flask, and under a nitrogen. This was followed by the addition of $0.6 \mathrm{~mL}$ of $28 \%$ ammonia. Upon sonication for $10 \mathrm{~min}$, the reaction mixture was heated to $80^{\circ} \mathrm{C}$ for $60 \mathrm{~min}$. The product was magnetically separated from the solution and washed until the solution reached neutral $\mathrm{pH}$. In the next process, magnetic silica nanoparticles, $\mathrm{Fe}_{3} \mathrm{O}_{4} @ \mathrm{SiO}_{2}$, were prepared according to the Ströber method ${ }^{40}$. This synthesis step has already been successfully used to obtain magnetic nanoparticles for a different purpose ${ }^{41}$. First, tetraethyl orthosilicate (TEOS) was dissolved in ethanol $\left(0.1 \mathrm{~mL}\right.$ TEOS per $1 \mathrm{~mL}$ of ethanol). TEOS solution ( $15 \mathrm{~mL}$ per $1 \mathrm{~g}$ of $\mathrm{Fe}_{3} \mathrm{O}_{4}$ ) was slowly added to a stable suspension of $\mathrm{Fe}_{3} \mathrm{O}_{4}\left(\mathrm{pH} 11\right.$ adjusted by ammonia) and then the mixture was stirred overnight. The product $\mathrm{Fe}_{3} \mathrm{O}_{4} @ \mathrm{SiO}_{2}$ was magnetically collected, washed several times with water and finally dried at $60^{\circ} \mathrm{C}$.

Dextran functionalized by 4-Amino-TEMPO (Dextran-NH-TEMPO) was obtained as follows: a solution of 4-amino-2,2,6,6-tetramethylpiperidine-N-oxyl (4-Amino-TEMPO) (0.171 g) in acetone was added to a solution of hexamethylene diisocyanate (HDIS) $(0.168 \mathrm{~g})$ in acetone ([HDIS]: [4-amino-TEMPO] =1: 1$)$. After the addition was completed, the solution was stirred for 3 hours, and then dextran $(0.120 \mathrm{~g})$ was added. The system was stirred for $12 \mathrm{~h}$.

Finally, Dextran-NH-TEMPO was used to cover and stabilize the magnetite particles. For this purpose the solvent from Dextran-NH-TEMPO solution was evaporated and $0.100 \mathrm{~g}$ of $\mathrm{Fe}_{3} \mathrm{O}_{4} @ \mathrm{SiO}_{2}$ in water was added. The mixture was intensively stirred for 1 hour and a stable product $\mathrm{Fe}_{3} \mathrm{O}_{4} @ \mathrm{SiO}_{2} @$ Dextran-NH-TEMPO in water was obtained.

Synthesis of $\mathrm{Fe}_{3} \mathrm{O}_{4} @ \mathrm{SiO}_{2} @ D$ Dextran-O-TEMPO was analogous whereby instead of 4-Amino-TEMPO, TEMPOL (O.172 g) was used.

The structures of $\mathrm{Fe}_{3} \mathrm{O}_{4} @ \mathrm{SiO}_{2} @$ Dextran-NH (or O)-TEMPO are presented in Fig. 9. 


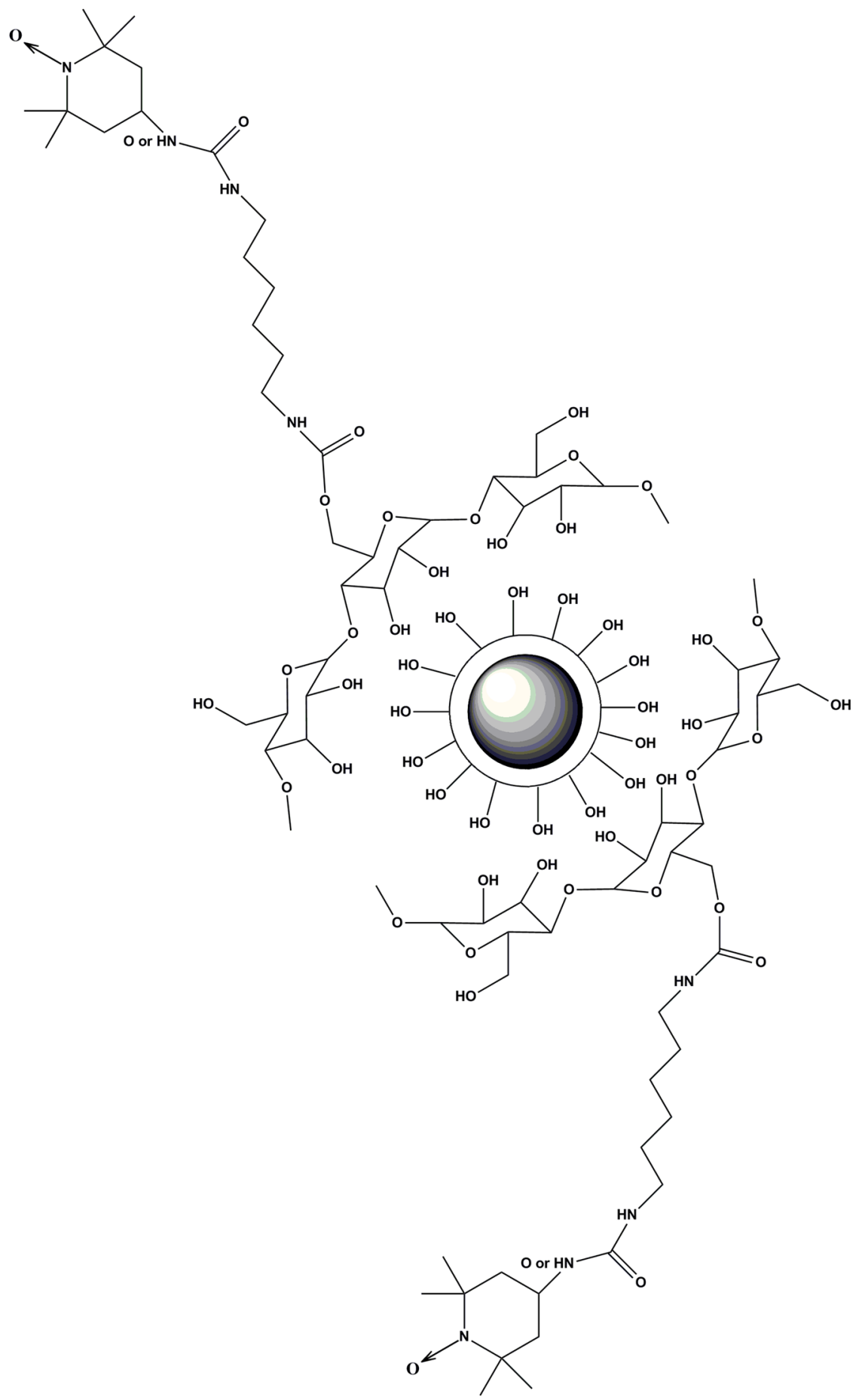

Figure 9. The structure of $\mathrm{Fe}_{3} \mathrm{O}_{4} @ \mathrm{SiO}_{2} @ D$ Dextran-NH-TEMPO and $\mathrm{Fe}_{3} \mathrm{O}_{4} @ \mathrm{SiO}_{2} @$ Dextran-O-TEMPO.

Synthesis of $\mathrm{Fe}_{3} \mathrm{O}_{4} @ \mathrm{SiO}_{2}$ @FITC. Fluorescent labeling of $\mathrm{Fe}_{3} \mathrm{O}_{4} @ \mathrm{SiO}_{2}$ with FITC (Fluorescein isothiocyanate) were synthesized in order to make confocal microscope experiment. The synthesis was carried out according to the procedures described by Yang et al. ${ }^{42}$ and Chekina et al. ${ }^{43}$. Initially silanization of $\mathrm{Fe}_{3} \mathrm{O}_{4}$ surfaces using tetraethyl orthosilicate was carried out and $\mathrm{Fe}_{3} \mathrm{O}_{4} @ \mathrm{SiO}_{2}$ was obtained. Then it was followed by a reaction with FITC. For this purpose, $0.02 \mathrm{~g}$ of FITC dissolved in acetone $(10 \mathrm{~mL})$ was added to a suspension containing $\mathrm{Fe}_{3} \mathrm{O}_{4} @ \mathrm{SiO}_{2}(0.1 \mathrm{~g})$ in acetone $(10 \mathrm{~mL})$. The resulting mixture was stirred and heated at constant temperature (40든 12 hours). The $\mathrm{Fe}_{3} \mathrm{O}_{4} @ \mathrm{SiO}_{2} @ \mathrm{FITC}$ were centrifuged, washed several times with the solvent used in the synthesis process, and finally dried at $40^{\circ} \mathrm{C}$. The $\mathrm{Fe}_{3} \mathrm{O}_{4} @ \mathrm{SiO}_{2} @ \mathrm{FITC}$ showed fluorescence characteristic of fluorescein.

Characterization methods. The magnetic nanoparticles were characterized using several conventional methods ${ }^{41,44}$. An IFS $66 \mathrm{v} / \mathrm{s}$ Fourier transform infrared (FTIR) spectrophotometer from Brucker (USA) was used 
to obtain infrared spectra. The samples were first powdered and the spectra were recorded in the $400-4000 \mathrm{~cm}^{-1}$ range. The FTIR spectrophotometer was equipped with MCT detector $\left(125 \mathrm{scans}\right.$, resolution $\left.2 \mathrm{~cm}^{-1}\right)$. Bruker AXS D8 Advance powder diffractometer (Germany) was used for collecting of X-ray diffraction (XRD) patterns. The diffractometer was equipped with Johansson monochromator $\left(\lambda \mathrm{Cu} \mathrm{K} \mathrm{K}_{\alpha 1}=1.5406 \AA\right)$. Transmission electron microscope (TEM) images of the samples were recorded on a Hitachi HT7700 microscope (Japan), while EDX patterns were obtained using energy dispersive X-ray (EDX) spectroscopy.

Yeast cells preparation. Bakery yeast (Saccharomyces cerevisiae) $(1 \mathrm{~g})$ were diluted in water $(50 \mathrm{ml})$ with addition of sugar $(0.3 \mathrm{~g})$ and incubated at $37^{\circ} \mathrm{C}$ for one hour.

Water solutions of functionalized magnetite nanoparticles mixed with yeast cells were also incubated during a few hours under the analogous conditions and studied at specified time intervals using the ESR method.

ESR measurements. Similarly to previous studies ${ }^{29-32}$ the electron spin resonance (ESR) measurements were made on an X-band Bruker EMX -10 spectrometer with $100 \mathrm{kHz}$ magnetic field second modulation frequency. Low temperatures, at which the ESR spectra were recorded, were controlled by a Bruker temperature control system ER 4131VT. The ESR spectra were recorded in a magnetic field sweep range of $650 \mathrm{mT}, 10 \mathrm{mT}$ and $1 \mathrm{mT}$. For the ESR spectra characteristic spectroscopic parameters were determined: g-spectroscopic splitting factor value, peak-to-peak line width $(\Delta \mathrm{H})$ and hyperfine splitting constant $(\mathrm{A})$ with the accuracy of \pm 0.0005 , $\pm 0.5 \mathrm{mT}$ and $\pm 0.5 \mathrm{mT}$, respectively.

The ESR spectra of pure spin labels solutions were investigated: TEMPO, TEMPOL, 4-Amino-TEMPO and 4-Carboxy-TEMPO, spin labels solutions with yeast cells, magnetic nanoparticles solutions with attached spin labels and solutions of magnetic nanoparticles functionalized with spin labels mixed with cells yeast.

ESR method provides information about samples of nanoparticles functionalized with spin labels, which relate to a magnetic core, a structure and dynamics of the surface of nanoparticles as well as their interaction with cells.

Confocal microscope. Confocal microscope Olympus FV1200 with an excitation laser with a wavelength of $488 \mathrm{~nm}$ was used to confirm the endocytosis process. The pictures were taken after one hour of incubation $\mathrm{Fe}_{3} \mathrm{O}_{4} @ \mathrm{SiO}_{2} @ \mathrm{FITC}$ with yeast cells at $37^{\circ} \mathrm{C}$.

\section{Data availability}

Data supporting the result of our study are available from the corresponding author upon request.

Received: 16 July 2019; Accepted: 20 November 2019;

Published online: 10 December 2019

\section{References}

1. Bhullar, S. K., Pal Singh, H., Kaur, G. \& Buttar, H. S. An Overview of the Applications of Nanomaterials and Development of Stents in Treating Cardiovascular Disorders. Rev. Adv. Mater. Sci. 44, 286-296 (2016).

2. Arivalagan, K., Ravichandran, S., Rangasamy, K. \& Karthikeyan, E. Nanomaterials and its Potential Applications. Int. J. Chem. Tech. Research 3(2), 534-538 (2011).

3. Bai, D.-P., Lin, X.-Y., Huang, Y.-F. \& Zhang, X.-F. Theranostics Aspects of Various Nanoparticles in Veterinary Medicine. Int. J. Mol. Sci. 19, 3299 (2018).

4. Liu, Y. et al. Metal-based NanoEnhancers for Future Radiotherapy: Radiosensitizing and Synergistic Effects on Tumor Cells. Theranostics 8(7), 1824-1849 (2018).

5. Lewandowski, M. \& Gwozdzinski, K. Nitroxides as Antioxidants and Anticancer Drugs. Int. J. Mol. Sci. 18, 2490 (2017).

6. Ma, Y., Mou, Q., Zhu, X. \& Yan, D. Small molecule nanodrugs for cancer therapy. Materials Today. Chemistry 4, 26-39 (2017).

7. Kumar, B., Jalodia, K., Kumar, P. \& Gautam, H. K. Recent advances in nanoparticle-mediated drug delivery. J. Drug Deliv. Sci. Tec. 41, 260-268 (2017).

8. Brzeziński, M., Wedepohl, S., Kost, B. \& Calderón, M. Nanoparticles from supramolecular polylactides overcome drug resistance of cancer cells. Eur. Polym. J. 109, 117-123 (2018).

9. Hałupka-Bryl, M. et al. Synthesis and in vitro and in vivo evaluations of poly(ethyleneglycol)-block-poly(4-vinylbenzylphosphonate) magnetic nanoparticles containing doxorubicin as a potential targeted drug delivery system. Colloid. Surface B 118, 140-147 (2014).

10. Krzyminiewski, R., Dobosz, B., Schroeder, G. \& Kurczewska, J. The principles of a new method, MNF-3D, for concentration of magnetic particles in three-dimensional space. Measurement 112, 137-140 (2017).

11. Krzyminiewski, R., Dobosz, B., Schroeder, G. \& Kurczewska, J. Focusing of $\mathrm{Fe}_{3} \mathrm{O}_{4}$ nanoparticles using a rotating magnetic field in various environments. Phys. Lett. A. 382, 3192-3196 (2018).

12. Hałupka - Bryl M. et al. Doxorubicin loaded PEG-b-poly(4-vinylbenzylphosphonate) coated magnetic iron oxide nanoparticles for targeted drug delivery. J. Magn. Magn. Mater. 384, 320-327 (2015).

13. Fürthauer, M. \& Smythe, E. Systems Dynamics in Endocytosis. Traffic 15, 338-346 (2014).

14. Di Fiore, P. P. \& von Zastrow, M. Endocytosis, Signaling, and Beyond. C. S. H. Perspect. Biol. 6, a016865 (2014).

15. Feyder, S., De Craene, J.-O., Bär, S., Bertazzi, D. L. \& Friant, S. Membrane Trafficking in the Yeast Saccharomyces cerevisiae Model. Int. J. Mol. Sci. 16, 1509-1525 (2015).

16. Goode, B. L., Eskin, J. A. \& Wendland, B. Actin and Endocytosis in Budding Yeast. Genetics 199, 315-358 (2015).

17. Maggio, N. D. et al. Rapid and efficient magnetization of mesenchymal stem cells by dendrimer functionalized magnetic nanoparticles. Nanomedicine-UK 11(12), 1515-1518 (2016).

18. Sun, M., Sun, B., Liu, Y., Shen, Q.-D. \& Jiang, S. Dual-Color Fluorescence Imaging of Magnetic Nanoparticles in Live Cancer Cells Using Conjugated Polymer Probes. Sci. Rep.-UK. 6, 22368 (2016).

19. Marcus, M. et al. Iron oxide nanoparticles for neuronal cell applications: uptake study and magnetic manipulations. J. Nanobiotechnol. 14, 37 (2016).

20. Mailänder, V. \& Landfester, K. Interaction of Nanoparticles with Cells. Biomacromolecules 10, 2379-2400 (2009).

21. de Castro, C. E. et al. Nanoparticle-Cell Interactions: Surface Chemistry Effects on the Cellular Uptake of Biocompatible Block Copolymer Assemblies. Langmuir 34, 2180-2188 (2018).

22. Krzyminiewski, R., Dobosz, B. \& Kubiak, T. The influence of radiotherapy on ceruloplasmin and transferrin in whole blood of breast cancer patients. Radiat. Environ. Bioph. 56, 345-352 (2017)

23. Bednarowicz, M. et al. ESR Studies of Redox-Active PMNT-PEG-PMNT Polymer. Mater. Chem. Phys. 161, 250-255 (2015). 
24. Kabacinska, Z., Krzyminiewski, R., Dobosz, B. \& Nawrocka, D. ESR investigation of structure and dynamics of paramagnetic centres in lime mortars from Budinjak, Croatia. Radiat. Meas. 47, 825-829 (2012).

25. Dobosz, B. et al. Free radicals, salicylic acid and mycotoxins in asparagus after inoculation with Fusarium proliferatum and F. Oxysporum. Appl. Magn. Reson. 41, 19-30 (2011).

26. Krzyminiewski, R. et al. EPR Study of Iron Ion Complexes in Human Blood. Appl. Magn. Reson. 40, 321-330 (2011).

27. Nesmelov, Y. E. \& Thomas, D. D. Protein structural dynamics revealed by site-directed spin labeling and multifrequency EPR. Biophys. Rev. 2, 91-99 (2010).

28. Czepas, J., Koceva-Chyła, A., Gwoździński, K. \& Jóźwiak, Z. Different effectiveness of piperidine nitroxides against oxidative stress induced by doxorubicin and hydrogen peroxide. Cell Biol. Toxicol. 24, 101-112 (2008).

29. Dobosz, B., Krzyminiewski, R., Schroeder, G. \& Kurczewska, J. Diffusion of functionalized magnetite nanoparticles forced by a magnetic field studied by EPR method. Curr. Appl. Phys. 16, 562-567 (2016).

30. Dobosz, B., Krzyminiewski, R., Schroeder, G. \& Kurczewska, J. Electron paramagnetic resonance as an effective method for a characterization of functionalized iron oxide. J. Phys. Chem. Solids 75, 594-598 (2014)

31. Dobosz, B., Krzyminiewski, R., Kurczewska, J. \& Schroeder, G. The dynamics of functionalized magnetite nanoparticles in various solutions studied by ESR method. Mater. Chem. Phys. 198, 297-302 (2017).

32. Dobosz, B., Krzyminiewski, R., Kurczewska, J. \& Schroeder, G. The influence of surface modification, coating agents and $\mathrm{pH}$ value of aqueous solutions on physical properties of magnetite nanoparticles investigated by ESR method. J. Magn. Magn. Mater. 429, 203-210 (2017).

33. Linh, P. H. et al. Dextran coated magnetite high susceptibility nanoparticles for hyperthermia applications. J. Magn. Magn. Mater. 460, 128-136 (2018).

34. Mitchell, J. B. et al. Biologically Active Metal-Independent Superoxide Dismutase Mimics. Biochemistry-US 29, 2802-2807 (1990).

35. Samuni, A., Carmichael, A. J., Russo, A., Mitchell, J. B. \& Riesz, P. On the spin trapping and ESR detection of oxygen-derived radicals generated inside cells. P. Natl. Acad. Sci. USA 83, 7593-7597 (1986).

36. Akdogan, Y., Emrullahoglu, M., Tatlidil, D., Ucuncu, M. \& Cakan-Akdogan, G. EPR studies of intermolecular interactions and competitive binding of drugs in a drug-BSA binding model. Phys. Chem. Chem. Phys. 18, 22531 (2016).

37. Samuni, A. M., DeGra, W., Krishna, M. C. \& Mitchell, J. B. Cellular sites of $\mathrm{H}_{2} \mathrm{O}_{2}$-induced damage and their protection by nitroxides. Biochim. Biophys. Acta 1525, 70-76 (2001)

38. Soule, B. P. et al. The chemistry and biology of nitroxide compounds. Free Radical Bio. Med. 42, 1632-1650 (2007).

39. Yurenya, A. Y. et al. The magnetic introduction of magnetite nanoparticles into live cells for radiosensibility enhancement. J. Magn. Magn. Mater. 427, 111-113 (2017).

40. Stöber, W., Fink, A. \& Bohn, E. J. Controlled growth of monodisperse silica spheres in the micron size range. J. Colloid Interf. Sci. 26, 62-69 (1968)

41. Kurczewska, J., Cegłowski, M. \& Schroeder, G. Preparation of multifunctional iron oxide nanoparticles for drug delivery. Mater. Chem. Phys. 211, 34-41 (2018).

42. Yang, H. et al. VCAM-1-targeted core/shell nanoparticles for selective adhesion and delivery to endothelial cells with lipopolysaccharide-induced inflammation under shear flow and cellular magnetic resonance imaging in vitro. Int. J. Nanomed. 8, 1897-1906 (2013).

43. Chekina, N. et al. Fluorescent magnetic nanoparticles for biomedical applications. J. Mater. Chem. 21, 7630-7639 (2011).

44. Kurczewska, J., Cegłowski, M., Messyasz, B. \& Schroeder, G. Dendrimer-functionalized halloysite nanotubes for effective drug delivery. Appl. Clay Sci. 153, 134-143 (2018).

\section{Acknowledgements}

This research did not receive any specific grant from funding agencies in the public, commercial, or not-for-profit sectors.

\section{Author contributions}

R.K.: conception and design of the work, the analysis and interpretation of data, manuscript preparation; B.D.: the acquisition, analysis and interpretation of data, manuscript preparation; G.S.: nanoparticles synthesis and characterization, participation in interpretation of data; J.K.: nanoparticles synthesis and characterization, participation in manuscript preparation (synthesis and characterization of nanoparticles), linguistic corrections of the manuscript. All authors have approved the submitted version of this manuscript.

\section{Competing interests}

The authors declare no competing interests.

Additional information

Supplementary information is available for this paper at https://doi.org/10.1038/s41598-019-55335-z.

Correspondence and requests for materials should be addressed to B.D.

Reprints and permissions information is available at www.nature.com/reprints.

Publisher's note Springer Nature remains neutral with regard to jurisdictional claims in published maps and institutional affiliations.

(c) (i) Open Access This article is licensed under a Creative Commons Attribution 4.0 International License, which permits use, sharing, adaptation, distribution and reproduction in any medium or format, as long as you give appropriate credit to the original author(s) and the source, provide a link to the Creative Commons license, and indicate if changes were made. The images or other third party material in this article are included in the article's Creative Commons license, unless indicated otherwise in a credit line to the material. If material is not included in the article's Creative Commons license and your intended use is not permitted by statutory regulation or exceeds the permitted use, you will need to obtain permission directly from the copyright holder. To view a copy of this license, visit http://creativecommons.org/licenses/by/4.0/.

(C) The Author(s) 2019 